\title{
Antitumor activity of baicalein on the mice bearing U14 cervical cancer
}

\author{
Yong Peng ${ }^{1,2}$, Qingwang $\mathrm{Li}^{1,3 \star}$, Kun $\mathrm{Li}^{1}$, Hongwei Zhao ${ }^{1}$, Zengsheng Han ${ }^{1}$, Fenglin $\mathrm{Li}^{4}$, Man \\ Sun $^{2}$ and Yanxia Zhang ${ }^{2}$ \\ ${ }^{1}$ Department of Biological Engineering, College of Environment and Chemical Engineering, Yanshan University, \\ Qinhuangdao, Hebei Province, 066004, People's Republic of China. \\ ${ }^{2}$ Department of Biomedical Engineering, College of Electrical Engineering, Yanshan University, Qinhuangdao, Hebei \\ Province, 066004, People's Republic of China. \\ ${ }^{3}$ Department of Animal Science, Northwest Agriculture and Forestry University, Yangling, Shanxi Province, 712100 \\ People's Republic of China. \\ ${ }^{4}$ Department of Bioengineering, Jilin Agricultural Science and Technology College, Jilin, Jilin Province, 132101, People's \\ Republic of China.
}

Accepted 12 September, 2011

\begin{abstract}
Baicalein is one of the major constituents of Scutellaria baicalensis, and some cancer cells could be inhibited by it according to some studies in recent years. Mice tumor models of U14 cervical cancer was established in our study, baicalein of high and low dose (40 and $20 \mathrm{mg} / \mathrm{kg}$, respectively) were given orally to mice. The tumor inhibition rates and the thymus (spleen) weight index were studied, the cell morphologies of tumor, liver and kidney were examined after HE stained, the percentage of apoptotic cells was detected by flow cytometer and the positive expression rates of $\mathrm{Bcl}-2$ and Bax protein in tumor tissues were examined by the standard immunehistochemical SP method. The results showed that baicalein could inhibit the tumor growth obviously with the tumor inhibition rate of $58.98 \%$. Besides, the apoptosis of tumor could be induced by baicalein with the apoptotic percentage of $16.92 \pm$ $0.65 \%$. Moreover, compared with the negative control group, the expression of $\mathrm{Bcl}-2$ was reduced, while that of Bax was increased after the treatment of Baicalein. So, baicalein could inhibit the growth of U14 cervical cancer cells, and it might induce apoptosis by downregulating the level of Bcl-2 protein and upregulating that of Bax.
\end{abstract}

Key words: Baicalein, U14 cervical cancer, Bcl-2, Bax, apoptosis.

\section{INTRODUCTION}

Baicalein $\left(5,6,7\right.$-trihydroxyflavone, BAE, $\left.\mathrm{C}_{15} \mathrm{H}_{10} \mathrm{O}_{5}\right)$ is one of the principle flavonoids extracted from the dry root of Scutellaria baicalensis and the ratio of baicalein to the dry material is about $5.41 \%$ (Min, 2009). It is also one of the major bioactive constituents of $S$. baicalensis and has a distinct structure as depicted in Figure 1. It has been reported that baicalein has a variety of pharmacological effects, including anti-microbial, anti-viral, antiinflammatory, anti-oxidant, scavenging oxygen free radicals, anti-cancer, anti-coagulant, anti-thrombotic, liver

*Corresponding author. E-mail: PY81@sina.com. Tel: 03358074662. Fax: 0335-8074662. protection (Zhang et al., 2001) and so on. It has been discovered that baicalein can inhibit the proliferation of some cancer cells, such as breast cancer (Po et al., 2002), ovarian cancer ( $\mathrm{Li}$ et al., 2004), gastric cancer (Xie et al., 2006), liver cancer (Chen et al., 2009), esophageal cancer (Yao and Guo, 2010) and so forth. However, the inhibition effect and detailed mechanism of the treatment with baicalein on cervical cancer is not very clear up till now.

In the present study, we investigated the anticancer effect of baicalein on the mice bearing U14 cervical cancer and attempted to elucidate the possible mechanism behind it by detecting some indicators, so as to provide the scientific basis for the inhibition effect of baicalein on cervical cancer. 


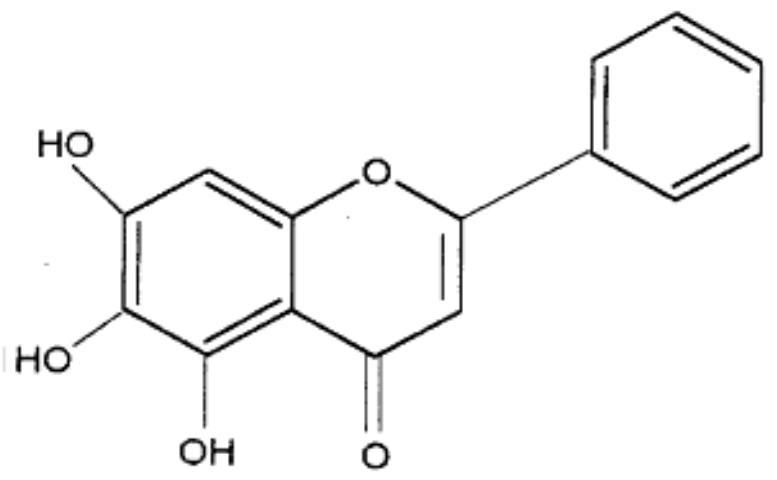

Figure 1. The structure of baicalein.

\section{MATERIALS AND METHODS}

Female Kun Ming mice of 6 weeks old (17 to $21 \mathrm{~g}$ ) were provided by the Experimental Animal Center of Chinese Military Academy of Medical Sciences, with Lot Number SCXK-(Army) 2007-004. Mice were kept in plastic cages in a clean room with appropriate temperature $\left(20 \pm 1^{\circ} \mathrm{C}\right)$ and humidity, and provided 8 to $10 \mathrm{~h}$ illumination every day. They were fed with a standard pellet diet and water ad libitum. The animals were treated according to the National Institute of Health Guide for the Care and Use of Laboratory Animals and their experimental use was approved by the Animal Ethics Committee of the University.

\section{Chemicals and reagents}

CTX (Cyclophosphamide) was purchased from Shanxi Powerdone Pharmaceutical Co., Ltd. in China, with Lot number 1008421, and diluted to the concentration of $25 \mathrm{mg} / \mathrm{kg}$ by physiological saline before use. Baicalein was provided by Nanjing ZeLang Medical Technology Co., Ltd. in China, and the determined purity was $98 \%$. HE (Hematoxylin and Eosin) staining kit was obtained from Beyotime Institute of Biotechnology in China, annexin V-FITC apoptosis detection kit was obtained from Nanjing KeyGen Biotech. Co., Ltd. in China, immunohistochemical staining kit and concentrated DAB kit were purchased from Zhongshan Goldenbridge Biotechnology Co., Ltd. in China, while rabbit anti$\mathrm{Bcl}-2$ and anti-Bax were purchased from Beijing biosynthesis biotechnology Co., Ltd. in China. All other chemicals used were of analytical grade.

\section{Cell Lines}

Mouse U14 cervical cancer cell line was obtained from the Peking Cancer Hospital Cell Bank of Chinese Academy Medical Sciences, and placed in Kun Ming mice abdomen.

\section{Establishment of mice cervical cancer models}

The experimental mice were divided into 4 groups randomly consisting of 10 mice per group. The 4 groups were designated as tumor control group, CTX treated group, baicalein high dose $(40 \mathrm{mg} / \mathrm{kg})$ and low dose $(20 \mathrm{mg} / \mathrm{kg})$ treated groups. Under sterile condition, $0.2 \mathrm{ml} \mathrm{U14}$ cells $\left(5 \times 10^{6} \mathrm{cell} / \mathrm{ml}\right)$ were injected into the left axilla S.C. per mouse. The rate of successful inoculation was $100 \%$.

\section{Effect of baicalein on U14 solid tumor growth}

After $24 \mathrm{~h}$ of tumor inoculation, baicalein was given orally at a dose of 40 and $20 \mathrm{mg} / \mathrm{kg}$ body weight, $(0.2 \mathrm{ml} /$ day $)$ respectively according to pre-test and the dose of active screening. The group administered with vehicle alone (distilled water, $0.2 \mathrm{ml} /$ day, p.o.) was taken as control, while the group treated with CTX $(25 \mathrm{mg} / \mathrm{kg}$, $0.1 \mathrm{ml} /$ day, i.p.) was considered as the standard reference drug. All groups were continuously treated for 14 days. The living conditions of mice were observed every day, and the changes of tumor volume and body weight were monitored. On day 15, all animals were killed and the transplanted tumors of treated and control mice were harvested and weighed. The tumor inhibition rate was calculated by the formula: $(C-T) / C \times 100 \%$, where "T" and " $\mathrm{C}$ " mean average tumor weight of treated groups and control group respectively.

\section{Effect of baicalein on thymus and spleen weight index in mice bearing tumor}

By the end of the experiment on day 15, the thymus and spleen of executed mice of all groups were collected and weighed, then the thymus and spleen weight indexes were calculated by the follow formulas:

Thymus weight index $=$ the average thymus weight $(\mathrm{mg}) /$ the average body weight $(\mathrm{g})$

Spleen weight index $=$ the average spleen weight $(\mathrm{mg}) /$ the average body weight (g)

\section{Effect of baicalein on tumor, liver and kidney in mice bearing tumor}

The tumor, liver and kidney of treated and control mice were excised and fixed in $10 \%$ neutral formalin at $4^{\circ} \mathrm{C}$, embedded in paraffin, and cut into $4 \mu \mathrm{M}$ sections for histology study. The sections were stained with HE staining method and then examined for cell morphology by light microscope.

\section{Effect of baicalein on apoptosis of tumor cells}

The tumor tissues of all groups were cut into pieces and made into single cell suspension by filtering through 200 mesh nylon net. The cell concentration was adjusted to $1 \times 10^{6}$ cells $/ \mathrm{ml}$ after being 
Table 1. Effect of baicalein on solid tumor growth.

\begin{tabular}{|c|c|c|c|c|c|}
\hline \multirow{2}{*}{ Group } & \multirow{2}{*}{ Treatment (mg/kg) } & \multicolumn{2}{|c|}{ Body weight (g) } & \multirow{2}{*}{$\begin{array}{c}\text { Tumor weight } \\
\text { (g) }\end{array}$} & \multirow{2}{*}{$\begin{array}{c}\text { Inhibition rate } \\
(\%)\end{array}$} \\
\hline & & Beginning & End & & \\
\hline Control & Vehicle & $20.68 \pm 1.32$ & $26.08 \pm 2.73$ & $2.56 \pm 0.14$ & - \\
\hline CTX & 25 & $20.83 \pm 1.52$ & $20.15 \pm 1.79$ & $0.86 \pm 0.09^{a}$ & $68.00 \%$ \\
\hline High dose of baicalein & 40 & $20.15 \pm 0.86$ & $21.83 \pm 0.70$ & $1.05 \pm 0.08^{a, b}$ & $58.98 \%$ \\
\hline Low dose of baicalein & 20 & $20.10 \pm 1.52$ & $23.82 \pm 1.65$ & $1.39 \pm 0.13^{\mathrm{a}, \mathrm{b}}$ & $45.62 \%$ \\
\hline
\end{tabular}

$\mathrm{n}=10$; (mean \pm S.D., g); $\mathrm{a}: P<0.05$ as compared with control group; $\mathrm{b}: P<0.05$ as compared with CTX group.

Table 2. Effect of baicalein on thymus and spleen weight index.

\begin{tabular}{lccc}
\hline Group & Treatment $(\mathbf{m g} / \mathbf{k g})$ & Thymus index $(\mathbf{m g} / \mathbf{g})$ & Spleen index $(\mathbf{m g} / \mathbf{g})$ \\
\hline Control & Vehicle & $4.1134 \pm 0.1238^{\mathrm{a}}$ & $21.7873 \pm 1.9241^{\mathrm{a}}$ \\
CTX & 25 & $0.6178 \pm 0.0014$ & $5.2442 \pm 0.6507$ \\
High dose of baicalein & 40 & $3.2124 \pm 0.1778^{\mathrm{a}, \mathrm{b}}$ & $8.3562 \pm 0.4487^{\mathrm{a}, \mathrm{b}}$ \\
Low dose of baicalein & 20 & $2.5012 \pm 0.0754^{\mathrm{a}, \mathrm{b}}$ & $12.0057 \pm 1.1681^{\mathrm{a}, \mathrm{b}}$ \\
\hline
\end{tabular}

$\mathrm{n}=10$; (mean \pm S.D., $\mathrm{mg} / \mathrm{g}$ ); a: $P<0.05$ as compared with CTX group; $\mathrm{b}: P<0.05$ as compared with control group.

centrifuged and washed 3 times.

The cells were overnight fixed with cold $70 \%$ ethanol, mixed with Annexin V-FITC, and then stained with PI (propidium iodide) solution consisting of RNase for $15 \mathrm{~min}$. The percentage of apoptotic cells was detected by flow cytometer using multicycle AV and the excitation wavelength was $488 \mathrm{~nm}$. The results were handled as follows: cells in lower left quadrant (Annexin V (-) / PI ()) were considered as living cells, cells in lower right quadrant (Annexin $\mathrm{V}(+)$ / PI (-)) were apoptotic cells, cells in upper right quadrant (Annexin V (+) / PI (+)) were necrotic or advanced apoptotic cells, while those in upper left quadrant (Annexin V (-) / PI $(+))$ were cellular debris.

\section{Effect of baicalein on expression of Bcl-2 and Bax protein in} tumor tissues

The harvested tumors of all groups were fixed in $10 \%$ formalin, embedded in paraffin and cut into $4 \mu \mathrm{m}$ sections. Tumor tissue sections were stained with the standard immunohistochemical SP (streptavidin peroxidase conjunction) method and stained with $\mathrm{DAB}$, and then the sections were mounted with neutral gum and observed under light microscope. The number of $\mathrm{Bcl}-2$ and $\mathrm{Bax}$ positive cells were counted with a hemacytometer under $400 \times$ magnification and the mean number was calculated.

\section{Statistical analysis}

The data were expressed as mean \pm S.D. The statistical analysis was performed by one-way analysis of variance, and differences between means were tested using Duncan's multiple range tests. $P$-values of less than 0.05 were considered significant in statistics. The statistical software SPSS13.0 was used for the data processing.

\section{RESULTS}

\section{Effect of baicalein on U14 solid tumor growth}

Compared with the tumor weight of the control group, the tumor weight of the CTX group and the baicalein groups were reduced respectively $(P<0.05)$ and the tumor weight of the baicalein groups were bigger than that of the CTX group $(P<0.05)$. However, there was no difference among the baicalein groups with each other $(P>0.05)$. Both of the baicalein groups could inhibit the tumor growth significantly $(P<0.05)$ and the tumor inhibition rates of the high and low dose baicalein groups were 58.98 and $45.62 \%$ respectively (Table 1 ). The mice in the baicalein groups were all in good spirits. At the end of the experiment, the mice in the CTX group lost their appetite, were in bad condition and the final body weight were decreased obviously. While the body weight of the other 3 groups were increased compared with the beginning and the mice of the baicalein groups were in good situation, water and food they took in were similar to normal mice. Moreover, the mice of the baicalein groups were more sensitive to stimulation, and the color and smoothness of fur were better than those of the CTX group.

\section{Effect of baicalein on thymus and spleen weight index in mice bearing tumor}

As shown in Table 2, compared with the CTX group, the thymus and spleen indexes of the baicalein groups were 


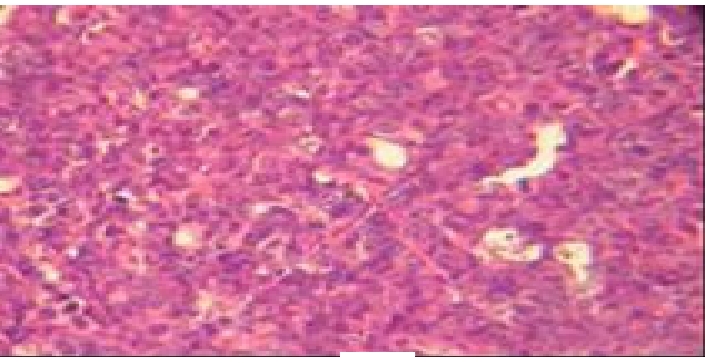

A

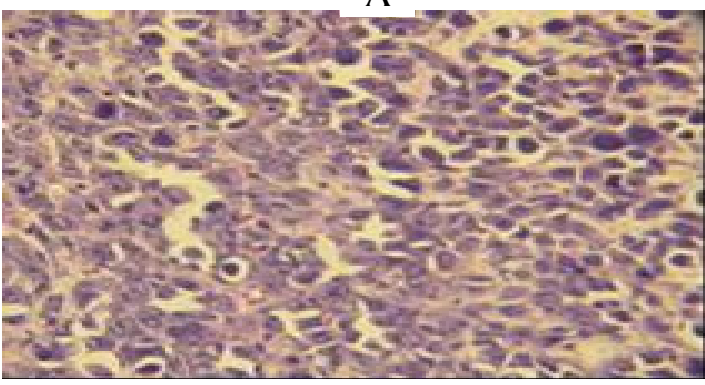

$\mathrm{C}$

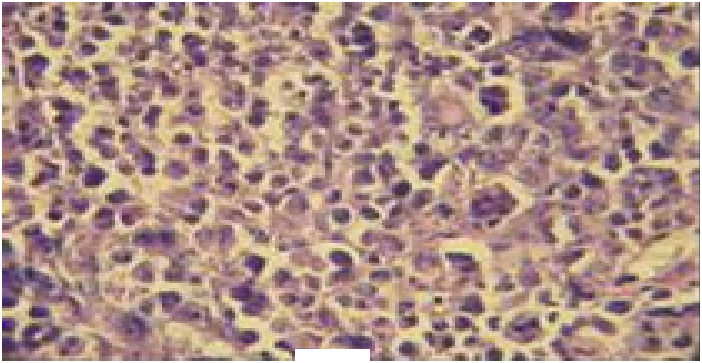

B

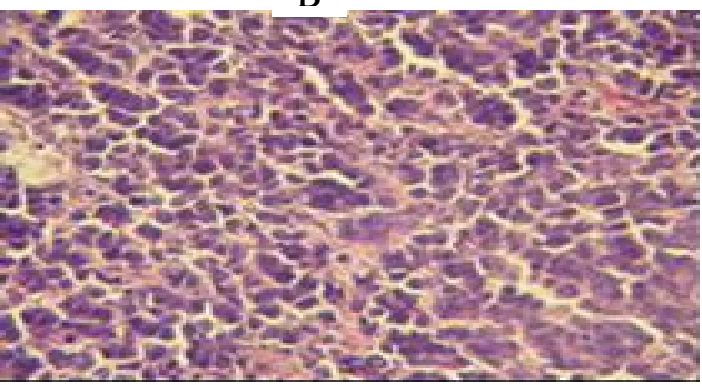

D

Figure 2. Tumor tissue sections of HE staining $(10 \times 40)$. (A) Tumor tissue section of control group, (B) Tumor tissue section of CTX group, (C) Tumor tissue section of high dose baicalein group, (D) Tumor tissue section of low dose baicalein group.

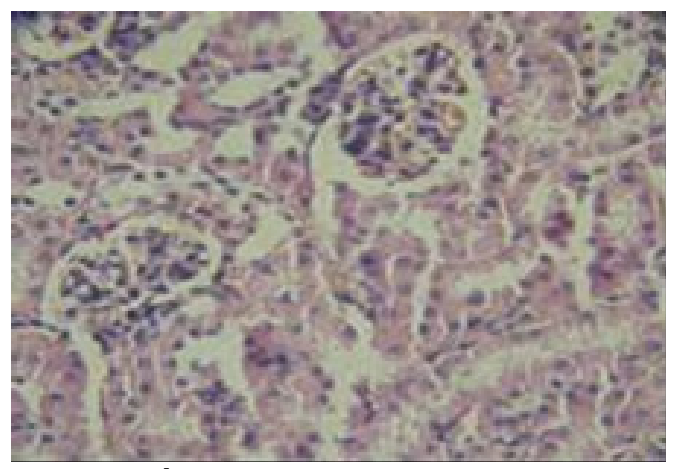

A

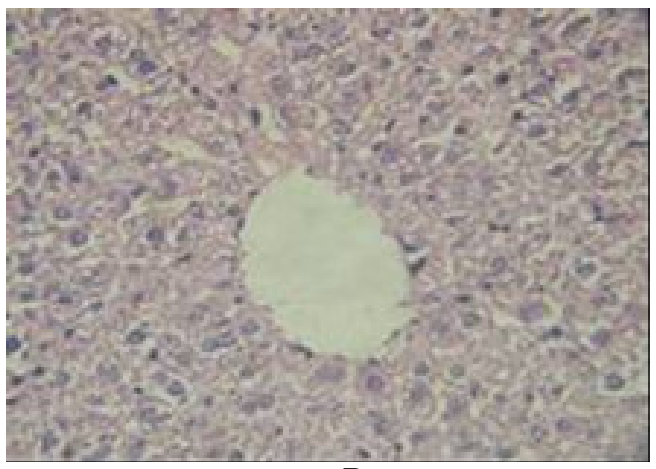

$\mathrm{B}$

Figure 3. Kidney and liver tissues sections of HE staining $(10 \times 40)$. (A) Kidney tissue sections of high dose baicalein group, (B) Liver tissue sections of low dose baicalein group.

increased dramatically. The thymus weight index of high dose of baicalein was increased to $3.2124 \pm 0.1778$ $\mathrm{mg} / \mathrm{g}$, while the spleen weight index was increased to $8.3562 \pm 0.4487 \mathrm{mg} / \mathrm{g}$. The thymus weight index of low dose of baicalein was $2.5012 \pm 0.0754 \mathrm{mg} / \mathrm{g}$, the spleen weight index was $12.0057 \pm 1.1681 \mathrm{mg} / \mathrm{g}$. Both the thymus weight and spleen weight indexes of the baicalein groups were increased significantly in contrast to the CTX group $(P<0.05)$. The thymus index and spleen index of the baicalein groups were less than those of the control group $(P<0.05)$, and there was no significant difference between the high and low dose of the baicalein group (P>0.05).

\section{Observation of cell morphology of tumor, liver and kidney}

The forms of tumor cells in all groups were observed after HE staining. The number of tumor cells in the CTX group and baicalein groups was reduced obviously compared with the tumor control group (Figure 2). The color and texture of liver and kidney were observed with naked eyes and there were no toxic effects on liver and kidney tissue. Then we conducted pathological examination of liver and kidney by HE staining. As shown in Figure 3, there were no obviously pathological changes in liver and kidney tissues of baicalein groups, the color, gloss and 
Table 3. Effect of Baicalein on apoptosis of tumor cells.

\begin{tabular}{lcc}
\hline Group & Treatment $\mathbf{( m g / k g )}$ & Percentage of apoptosis cells (\%) \\
\hline Control & Vehicle & $10.86 \pm 0.37$ \\
CTX & 25 & $27.52 \pm 0.32^{\mathrm{a}}$ \\
High dose of baicalin & 40 & $16.92 \pm 0.65^{\mathrm{a}, \mathrm{b}}$ \\
Low dose of baicalin & 20 & $12.42 \pm 0.70^{\mathrm{a}, \mathrm{b}}$ \\
\hline
\end{tabular}

$\mathrm{n}=10$; (mean \pm S.D., \%); a: $P<0.05$ as compared with control group; $\mathrm{b}: P<0.05$ as compared with CTX group.

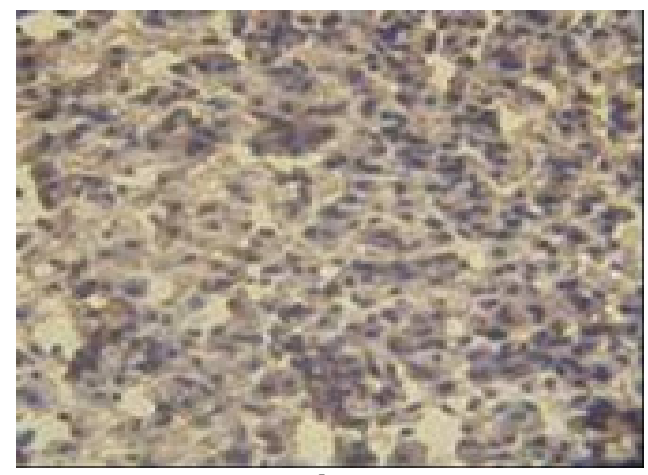

A

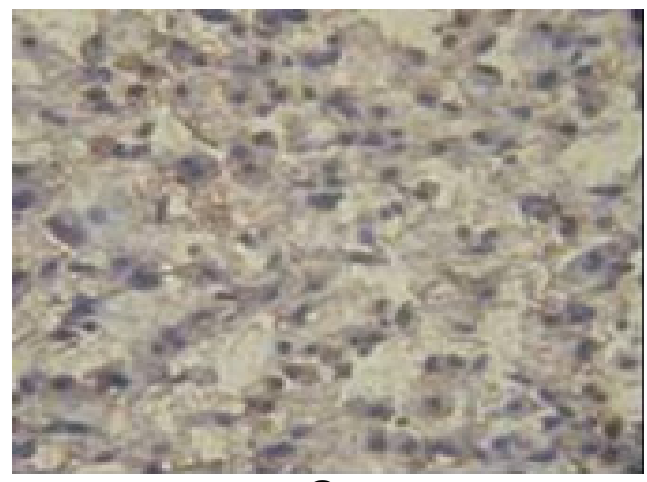

C

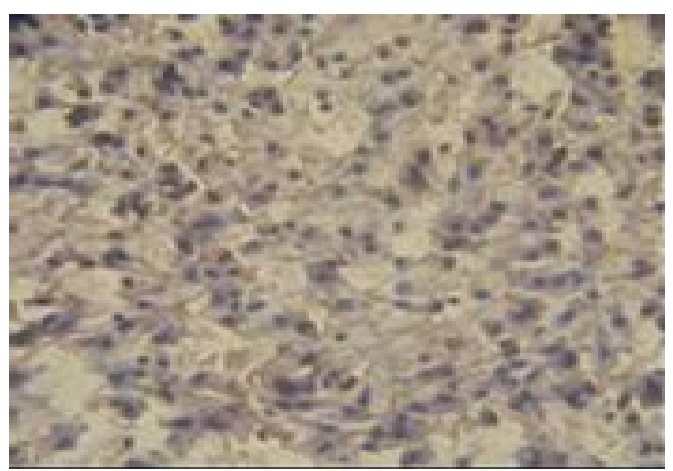

$\mathrm{B}$

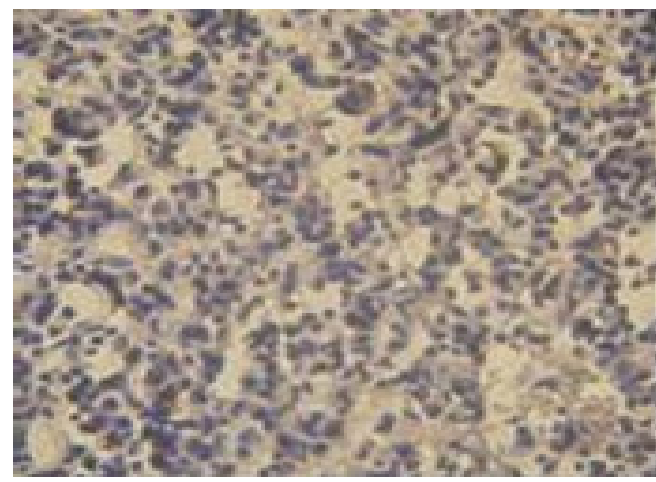

$\mathrm{D}$

Figure 4. Effect of baicalein on the expression of Bax protein $(10 \times 40)$. (A) Control group, (B) CTX group, (C) high dose baicalein group and (D) low dose baicalein group.

texture were normal. The sections of liver and kidney showed that central vein and hepatic lobule were clear, glomerular and renal tubular were also evident. The data indicate that the administration of baicalein of both doses did not affect liver and kidney tissues.

\section{Effect of baicalein on apoptosis of tumor cells}

The percentage of apoptotic cells in the control group was $10.86 \pm 0.37 \%$. The percentage of apoptotic cells in the CTX group, the high and the low baicalein group were increased respectively (Table 3 ). There was a significant increase on the percentage of apoptotic cells in the baicalein groups compared with the control group $(P<0.05)$. However, there was a significant reduction in the percentage of apoptotic cells of the baicalein groups compared to the CTX group $(P<0.05)$, but there was no significant difference between the high and low dose of baicalein group $(P>0.05)$.

\section{Effect of baicalein on expression of $\mathrm{Bcl}-2$ and $\mathrm{Bax}$ protein in tumor tissues}

The percentage of Bax positive cells in the control group was $13.33 \pm 0.62 \%$, while the percentages of the baicalein groups and the CTX group were increased significantly $(P<0.05) \quad$ (Figure 4 and Table 4$)$. The percentage of Bcl-2 positive cells in the control group was $53.28 \pm 0.46 \%$, while the percentages of the baicalein groups were $42.83 \pm 2.33$ and $46.21 \pm 1.64 \%$, in high and 
Table 4. Effect of baicalein on the expression of Bcl-2 and Bax protein.

\begin{tabular}{lcccc}
\hline Group & Treatment $(\mathbf{m g} / \mathbf{k g})$ & Bcl-2 positive cells $(\%)$ & Bax positive cells (\%) & Bax/Bcl-2 \\
\hline Control & Vehicle & $53.28 \pm 0.46$ & $13.33 \pm 0.62$ & 0.25 \\
CTX & 25 & $35.42 \pm 0.82^{\mathrm{a}}$ & $35.12 \pm 0.93^{\mathrm{a}}$ & 0.99 \\
High dose of baicalein & 40 & $42.83 \pm 2.33^{\mathrm{a}, \mathrm{b}}$ & $26.32 \pm 1.41^{\mathrm{a}, \mathrm{b}}$ & 0.61 \\
Low dose of baicalein & 20 & $46.21 \pm 1.64^{\mathrm{a}, \mathrm{b}}$ & $20.63 \pm 1.05^{\mathrm{a}, \mathrm{b}}$ & 0.45 \\
\hline
\end{tabular}

$\mathrm{n}=10$; (mean \pm S.D., \%); a: $P<0.05$ as compared with control group. b: $P<0.05$ as compared with CTX group.

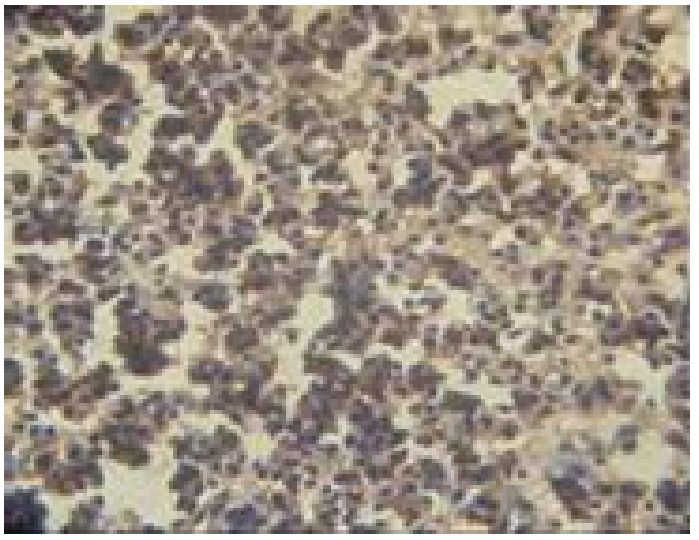

A

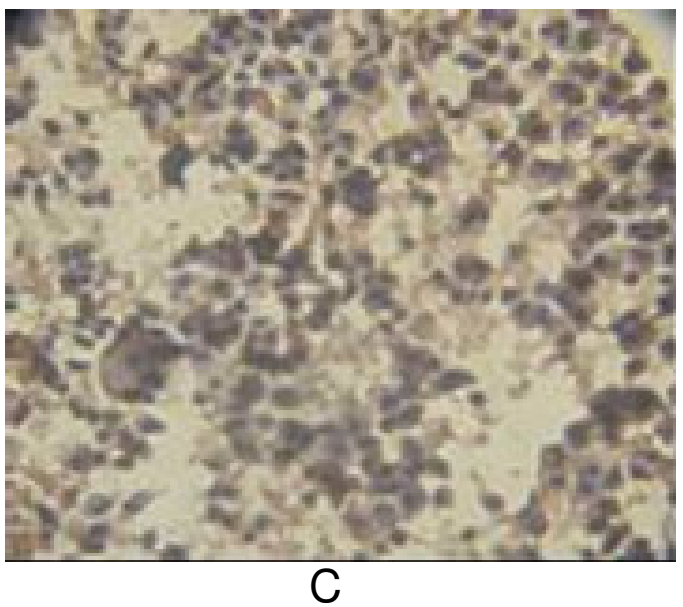

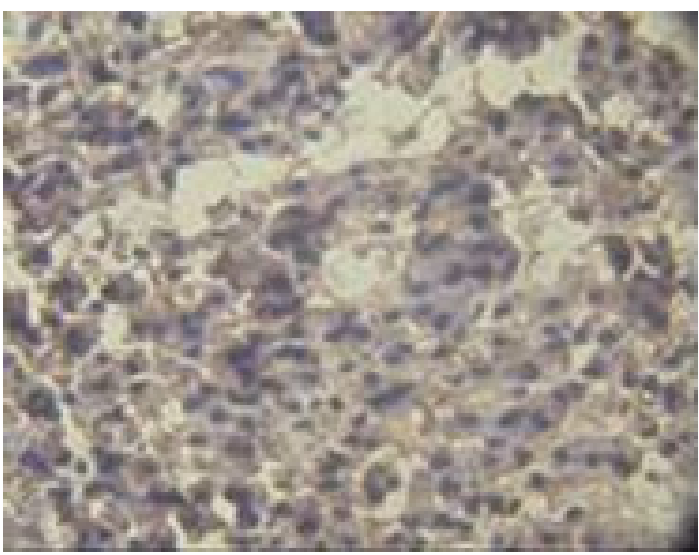

B

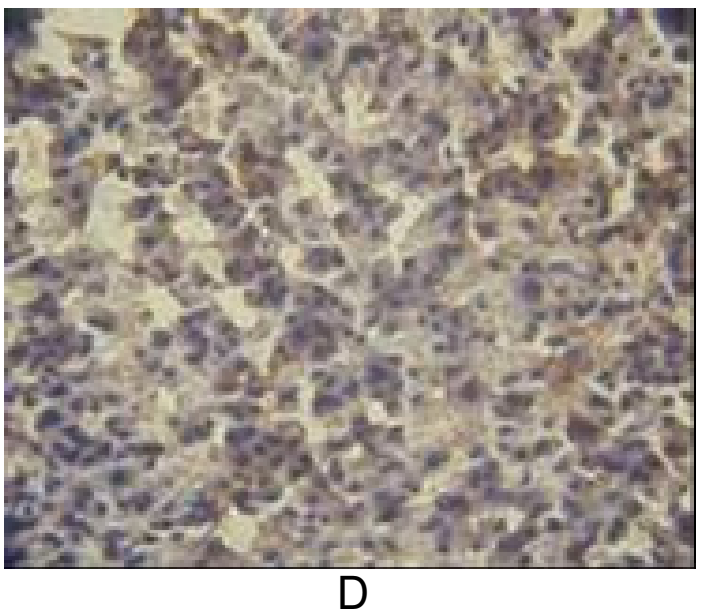

Figure 5. Effect of baicalein on the expression of Bcl-2 protein $(10 \times 40)$. (A) Control group, (B) CTX group, (C) high dose baicalein group and (D) low dose baicalein group.

low dose group respectively (Figure 5 and Table 4). Compared with the control group, both of the high dose and low dose of the baicalein groups could reduce the expression of $\mathrm{Bcl}-2$ and increase the expression of $\mathrm{Bax}$ $(P<0.05)$. Compared with the CTX group, the regulation effect on Bcl-2 and Bax in the baicalein groups was weaken, and the expression of $\mathrm{Bcl}-2$ was significantly increased, while the expression of Bax got a significantly decrease $(P<0.05)$. There was no obvious difference between the high and low dose of the baicalein groups on the expression of $\mathrm{Bcl}-2$ and $\mathrm{Bax}(P>0.05)$. The rate of
$\mathrm{Bax} / \mathrm{Bcl}-2$ in high dose of baicalein was 0.61 , while the rate in the low dose baicalein was 0.45 , the Bax/Bcl-2 rates of the baicalein groups were both increased compared with the control group $(P<0.05)$, and less than the CTX group (Table 4).

\section{DISCUSSION}

In recent years, flavonoids of $S$. baicalensis were studied deeply with the increasing researches on pharmacological 
effects of $S$. baicalensis. As the major constituent, baicalein attracted more concern. Baicalein could inhibit the growth of some cancer cells according to previous researches, and the possible mechanisms were: inducing apoptosis by regulating the related apoptosis protein and enhancing the activity of Caspase-3 (Li et al., 2004; Lee et al.,2008; Tong et al., 2009), inducing cell cycle arrest (Lee et al., 2005), declining the expression of VEGF, inhibiting the vessel from growing (Xie et al., 2006), inhibiting the invasion and migration of cancer cells (Wang et al., 2010a; Wang et al., 2010b) and so on. Tong et al. (2009) proposed that the possible mechanism of baicalein inducing Hela cells apoptosis may be related to induce cells apoptosis and enhancing the activity of Caspase-3.

According to our research, we found that baicalein might remarkably inhibit the growth of U14 cervical cancer tissues with the inhibition rate of $58.98 \%$ in the high dose group and $45.62 \%$ in the low dose group. The number of tumor cells in the high dose and low does baicalein groups was reduced obviously, and the rates of apoptosis in the baicalein groups were also increased. These results indicated that baicalein could induce the apoptosis of U14 cervical cancer cells. Observation from the pathological examination of liver and kidney indicated that there were no apparent pathological changes in the baicalein groups, which showed that baicalein almost had no toxic effects to liver and kidney tissues in model mice. It is well known that there is a close link between the occurrence and development of tumor and the decreased immune function of body. The immune dysfunction often occurred in cancer patients, however, most of anti-cancer drugs have great impact on immune function when destroying tumor cells, and cause the abnormality of immune organ index such as thymus and spleen. The report believes that the changes of the thymus and spleen weight index can reflect the state of immune function (Chen et al., 2010). The weight of immune organs and thymus (spleen) index can be used as indicators of determining immune function. Our research showed that baicalein could increase the mice thymus and spleen index significantly compared with CTX, and indicated that baicalein could enhance the immune function of tumor-bearing mice. $\mathrm{Bcl}-2$ is the major gene of inhibiting apoptosis which has the effects of inhibiting apoptosis and increasing cells lifetime. Meanwhile, Bax is a new gene which can promote apoptosis, and it can not only antagonize the effect of inhibiting apoptosis from Bcl2, but also promote apoptosis directly. Bax is distributed in cytoplasm mainly, while $\mathrm{Bcl}-2$ was distributed in cytoplasmic and mitochondrial membrane, and they can induce apoptosis of tumor cells through the mitochondrial pathway. Generally, Bax/Bcl-2 ratio is considered to be a key factor of affecting apoptosis, the heterodimer of Bcl-2 and Bax is increased when Bcl-2 in cells is increasing, and then the apoptosis trends were getting weaken. However, when Bax is increased, the homodimer formatted by Bax would charge, and the cells would go to apoptosis easily. So Bax/Bcl-2 ratio was important in determining whether cells would go into the state of apoptosis (Miao et al., 2005).Our results of immunehistochemical method showed that the Bax expression of tumor tissues in the high dose baicalein group increased,and the $\mathrm{Bcl}-2$ expression decreased, while the ratio of $\mathrm{Bax} / \mathrm{Bcl}-2$ increased to 0.61 compared with the control group. All of these results indicated that baicalein might induce the apoptosis of U14 cervical cancer cells by way of adjusting the expression of $\mathrm{Bcl}-2$ and $\mathrm{Bax}$, which was similar with the results that Li et al., (2009) got.

\section{Conclusion}

According to our experiment, we inferred that baicalein could inhibit the growth of U14 cervical cancer in vivo and it almost had no toxic effects on liver and kidney in mice models. Baicalein might induce the apoptosis of tumor tissues through the mitochondria (intrinsic) pathway which downregulated the level of anti-apoptotic protein $\mathrm{Bcl}-2$ and unregulated the level of pro-apoptotic protein Bax. Therefore, we propound that this might be one of the effective mechanisms on tumor. However, the detailed mechanism of inhibiting cervical cancer cells by baicalein still needs further researches.

\section{REFERENCES}

Chen $\mathrm{CH}$, Huang TS, Wong $\mathrm{CH}$, Hong $\mathrm{CL}$, Tsai YH, Liang CC, Lu FJ, Chang WH (2009). Synergistic anti-cancer effect of baicalein and silymarin on human hepatoma HepG2 Cells. Food Chem. Toxicol. 47(3): 638-644.

Chen WL, Li YQ, Luo PY, Sun XW (2010). Guizhil Fuling Pill on Mice Bearing Human Cervical Cancer Study on Mechanism of Immune Regulation. J. Practical Tradit. Chinese Internal Med. 24(6): 27-29.

Lee HZ, Leung HW, Lai MY, Wu CH (2005). Baicalein induced cell cycle arrest and apoptosis in human lung squamous carcinoma $\mathrm{CH} 27$ cells. Anticancer Res. 25(2A): 959-964.

Lee JH, Li YC, Ip SW, Hsu SC, Chang NW, Tang NY, Yu CS, Chou ST, Lin SS, Lino CC, Yang JS, Chung JG (2008). The role of $\mathrm{Ca}^{2+}$ in baicalein-induced apoptosis in human breast MDA-MB-231 cancer cells through mitochondria- and caspase-3-dependent pathway. Anticancer Res. 28(3A): 1701-1711.

Li DR, Zhang W, Tang DP, Tu WS, Qin Q (2004). A study of the reverse effect of scutellarein on multidrug-resistant human ovarian carcinoma cell line A2780/ADM. Tumor. 24(2):111-113.

Li YC, Tyan YS, Kuo HM, Chang WC, Hsia TC, Chung JG (2004). Baicalein induced in vitro apoptosis undergo caspases activity in human promyelocytic leukemia HL-60 cells. Food Chem Toxicol. 42(1):37-43.

Li YC, Lin HJ, Yang JH, Yang JS, Ho HC, Chang SJ, Hsai TC, Lu HF, Huang AC, Chung JG (2009). Baicalein-induced apoptosis via endoplasmic reticulum stress through elevations of reaction oxygen species and mitochondria dependent pathway in mouse-rat hybrid retina ganglion cells (N18). Neurochem Res. 34(3): 418-429.

Miao J, Lin ZQ, Wang XL, Dong XM (2005). Apoptosis-regulating gene $\mathrm{Bcl}-2$ and Bax expression in carcinogenesis of the cervix. Acad. J. Guangzhou Med. College, 33(1): 15-18.

Min LW (2009). New therapeutic aspects of flavones: The anticancer properties of Scutellaria and its main active constituents Wogonin, Baicalein and Baicalin. Cancer Treat Rev. 35(1): 57-68.

Po LS, Chen ZY, Tsang DS, Leung LK (2002). Baicalein and genistein 
display differential actions on estrogen receptor (ER) transactivation and apoptosis in MCF-7 cells. Cancer Lett. 187(1-2):33-40.

Tong XH, Dong SY, Tao $L$ (2009). Inhibitory effect of baicalein on human cervix cancer HeLa cells. J. Bengbu Med. Coll. 34(6): 468-470.

Wang L, Ling Y, Chen Y, Li CL, Feng F, You QD, Lu N, Guo QL (2010a). Flavonoid baicalein suppresses adhesion, migration and invasion of MDA-MB-231 human breast cancer cells. Cancer Lett. 297(1): 42-48.

Wang XF, Zhou QM, Su SB (2010b). Experimental study on Baicalein inhibiting the invasion and migration of human breast cancer cells. Chinese Pharmacological Bull., 26(6): 745-750.
Xie JW, Huang CM, Zhang XF, Lu HS (2006). Induction of apoptosis by baicalein on gastric cancer cell lines. J. Fujian Med. Univ. 40(1): 3536.

Yao HQ, Guo GH (2010). The effect of Baicalein on the proliferation and cell cycle of EC109. Guangdong Med. J. 31(2): 153-155.

Zhang XP, Li ZF, Liu XG (2001). Review in pharmacological study of baicalein. Chinese Pharmacol. Bull. 17(6):711-713. 